\title{
LOS NIÑOS MONSTRUOSOS EN EL ORFANATO DE JUAN ANTONIO BAYONA Y DISTANCIA DE RESCATE DE SAMANTA SCHWEBLIN
}

\author{
Rodrigo Ignacio González Dinamarca \\ Pontificia Universidad Católica de Chile \\ rigonza2@uc.cl
}

Recibido: 01-07-2015

Aceptado: 20-11-2015

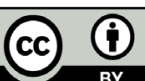

\section{RESUMEN}

Este artículo analiza la figura de los niños monstruosos en dos obras de ficción contemporáneas: la película El orfanato de Juan Antonio Bayona (2007) y la novela Distancia de rescate de Samanta Schweblin (2014). Los personajes infantiles juegan en ambas obras un rol decisivo, puesto que las dos tramas se construyen en torno al horror suscitado por los infantes, tanto en un sentido físico - en ambas obras la deformidad del cuerpo será un tema importante- como moral -los niños monstruosos son una entidad inquietante, ominosa (Freud, 1919). Por medio de un análisis comparativo, se busca dar cuenta de afinidades y discrepancias en la construcción de la figura del niño monstruoso, así como observar su función y relevancia en la producción del terror. Todo ello finalmente nos permitirá concluir que los niños monstruosos materializan temores y fantasías de los adultos, reflejando de este modo sus propias culpas (Martín Alegre, 2001).

Palabras clave: niños, monstruos, infancia, terror.

\section{AbStract}

This article analyzes the figure of monstrous children in two contemporary fiction works: the film El Orfanato by Juan Antonio Bayona (2007) and the novel Distancia de rescate by Samanta Schweblin (2014). The child characters play a decisive role in both works, as the two stories are constructed around the horror induced by the infants, both in a physical sense -in both works the body's deformity is an important issueand a moral one -the monstrous children are an astonishing, ominous entity (Freud, 1919). Through a comparative analysis, the intention is to account for affinities and 
discrepancies in the construction of the monstrous child's figure, as well as notice its function and relevance in the production of horror. All of it will finally allow us to conclude that the monstrous children materialize adults' fears and fantasies, reflecting in this way their own faults (Martín Alegre, 2001).

KEY wORDS: children, monsters, childhood, horror.

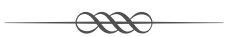

Concebir la infancia como una realidad tenebrosa, a nuestros propios niños como fuente de terror, puede parecernos en un comienzo una idea extraña. Ansiosos de aferrarnos todavía a las estructuras psíquicas que sostienen nuestro mundo, nos rehusamos a aceptar la posibilidad de que oculten un fondo macabro. En efecto, admitir por un instante que en ellos puedan residir fuerzas oscuras, y ver con qué facilidad la inocencia se disuelve para dar lugar a la amenaza, implica acceder al mundo distanciado del que hablara Wolfgang Kayser al enunciar su teoría sobre lo grotesco: «un mundo que se está desquiciando mientras ya no encontramos apoyo alguno» (1957: 32). Esta será, pues, la fuente del sentimiento suscitado por lo grotesco:

[N]osotros hemos concebido como característico de lo grotesco el que no se trata de un reino peculiar y sin relacionar y de un fantasear completamente libre [...] El mundo grotesco es nuestro mundo... y no lo es. El estremecimiento mezclado con la sonrisa tiene su base justamente en la experiencia de que nuestro mundo familiar -que aparentemente descansa en un orden fijo- se está distanciando por la irrupción de poderes abismales y se desarticula renunciando a sus formas, mientras se van disolviendo sus ordenaciones (1957: 40).

En definitiva, cuando hablamos de lo monstruoso en los niños, hemos de tener en cuenta que supone un desquiciamiento estructural. El infante es arrancado del lugar inocuo en el que ha sido puesto, como entidad que requiere protección y cuidados, y se revela de pronto como una amenaza. Es inevitable recordar también en este punto las ideas de Freud acerca de lo siniestro u ominoso - unheimlich-, categoría que designa «aquella variedad de lo terrorífico que se remonta a lo consabido de antiguo, a lo familiar desde hace largo tiempo» (Freud, 1919: párr. 6). Es este el efecto producido tras advertir lo monstruoso en el terreno de lo infantil, el desvanecimiento de la seguridad dada por el espacio familiar, y en su lugar la irrupción de lo horrible. 
Pero si atendemos a la naturaleza misma de la infancia, veremos que esta concepción no resulta, después de todo, tan descabellada. De acuerdo con autores como Terry Eagleton, «los niños son sólo unas criaturas a medio socializar de las que, de vez en cuando, se puede esperar conductas bastante salvajes» (2010: 9). El niño es una entidad pre-civilizada, todavía no conformada de acuerdo a los estamentos simbólicos que sustentan la cultura. Portador del misterio primigenio, el niño se ubica a medio camino entre lo animal y lo humano, entre la criatura y el ser como categoría social y política. En esta misma ambigüedad reside su carácter siniestro: «Como los niños no forman del todo parte del juego social, pueden ser vistos como seres inocentes; pero justamente por esa misma razón, también pueden ser considerados engendros de Satanás» (Eagleton, 2010: 10). El reverso de esta inocencia permitirá, pues, articularlos como figuras monstruosas, en la medida que surge una cara no prevista, un lado oscuro y ajeno a lo conocido:

[E]stamos dispuestos a creer toda clase de noticias siniestras referidas a los niños porque nos resultan como una especie de raza medio alienígena incrustada en nuestro seno. Como no trabajan, no está claro para qué sirven. No practican el sexo, aunque no es descartable que también eso se lo estén callando. Tienen la rareza de aquellas cosas que se parecen a nosotros en ciertos aspectos, pero no en otros. No es difícil, entonces, fantasear incluso con la idea de que estén conspirando colectivamente contra nosotros (Eagleton, 2010: 9)

La cuestión de la sexualidad señalada por Eagleton no es un detalle menor en la concepción del niño como una realidad monstruosa. De acuerdo con Auba Llompart Pons (2012), hemos de señalar que en el siglo xx, con el desarrollo de las teorías freudianas sobre el origen de la sexualidad en la infancia, la idea de la inocencia del niño se quebranta, y en su lugar se abre un abismo. En los infantes aparecen las mismas fuerzas incontrolables y voraces que mueven el actuar de los adultos:

El Eros y el Tánatos irrumpen [...] en la vida del niño, provocando el terror del adulto; la figura del niño empieza a cobrar una nueva dimensión: su inocencia comienza a ser cuestionada y cada vez está menos claro si el niño es una víctima o un peligro en potencia, una pequeña bestia que debe ser domada por el adulto [...] es esta asociación del niño con el Eros y el Tánatos [...], tradicionalmente vista como antinatural, la que convierte al niño monstruo en uno de los villanos más temibles del terror actual, debido al desconcierto que nos produce (Llompart Pons, 2012: 270-271). 
A su vez, la razón de este temor a las ideas sobre la sexualidad infantil radicaría, de acuerdo con Martín Alegre (2001: 106), en que desarman los esquemas tradicionales ofrecidos en el cómodo mundo victoriano, donde el niño aparecía como una entidad inofensiva y afable. Además, impelen a atender a las oscuras fuerzas que residirían al interior de los seres humanos desde su infancia, y a las que se ha intentado controlar por medio de una serie de normas: «The discovery of the child sexual life [...] horrified many adults, especially for what it said about their own digressions from normative sexuality» (Martín Alegre, 2001: 104). Es en este sentido que puede también leerse la monstruosidad de los niños, toda vez que quebrantan un sistema y que resultan inabarcables desde el discurso simbólico que sustenta a la sociedad: «Transgresión [...] de los límites naturales, transgresión de las clasificaciones, transgresión del marco, transgresión de la ley como marco; en la monstruosidad, en efecto, se trata realmente de eso» (Foucault, 2000: 68). Esta transgresión que da forma al niño monstruoso se da, en suma, cuando en nuestro orden simbólico la infancia deja de pertenecer al ámbito de lo inocuo y aparece como una realidad amenazante, ya sea por el peligro que supone para las estructuras familiares establecidas, o bien para las formas de controlar las fuerzas eróticas y tanáticas que residen en el ser humano, todo lo cual desestabiliza las estructuras del ideal de familia patriarcal: «Just as children were infantilized in the past to signify the patriarch's total control of family life, they are now demonized to express the parent's failure to control them» (Martín Alegre, 2001: 107). En ese sentido, resulta clarificadora la afirmación de Foucault: «en cada época [...] hubo formas privilegiadas de monstruos» (2000: 72). El análisis del rol específico del monstruo, como entidad creada y proyectada desde la cultura, permite revelar las preocupaciones y temores que sobrevuelan el imaginario de la misma. En otras palabras, el surgimiento o explotación de una criatura monstruosa en un contexto específico da cuenta de cómo se articula el miedo a la ruptura de una norma particular. Así, hablar de niños monstruosos es hablar del temor a la destrucción de las jerarquías familiares y de las categorías que ordenan el mundo de la infancia y el de los adultos. Recordemos en este punto que «[e]l discurso sobre el monstruo [...] es siempre un discurso sobre el hombre, sobre su concepción del mundo, sobre su necesidad de regular y sobre sus miedos» (Salamanca Ballesteros, 2007: 18). De este modo, la construcción del niño monstruoso permitirá dilucidar, en última instancia, la presencia de una serie de fantasmas y temores ocultos del adulto acerca de su propia naturaleza.

Hay algo, pues, misterioso e inaprehensible en la esencia de los niños que permite visualizarlos como entidades ominosas. De ahí que algunos au- 
tores incluyan dentro de las estrategias a las que recurre el cine de terror -género en que se enmarca la cinta El orfanato- para producir un cierto efecto psicológico en el espectador: «centrar la amenaza en seres normalmente inofensivos, como ciertos animales [...] o niños» (Pérez y García, 2005: 241). Del primer caso sería ejemplo paradigmático el filme de Alfred Hitchcock Los pájaros s, mientras en el segundo encontramos una amplia tradición de películas de terror en las que el elemento atemorizante será el niño, entre las que pueden destacarse La mala semilla (LeRoy, 1956), El pueblo de los malditos (Ri1la, 1960; Carpenter, 1995), y ¿Quién puede matar a un niño? (Ibáñez Serrador, 1976). Incluso, la elaboración de las figuras infantiles en las ficciones de terror ha llegado a constituir algunos clichés, como el del típico niño silencioso y de aspecto enfermizo, que juega con amigos invisibles, hace unos dibujos horribles que predicen lo que ocurrirá, o es poseído por fuerzas desconocidas; un niño que, en fin, se mueve en una esfera que para los adultos parece estar vedada. Este prototipo infantil puede encontrarse ampliamente representado en películas emblemáticas del género, como El resplandor (Kubrik, 1980), Sexto sentido (Shyamalan, 1999) o El aro (Verbinski 2002). Y, por cierto, este cliché de la tradición hollywoodense tomará forma también en el personaje de Simón en El orfanato, personaje que juega con amigos invisibles y que, también, hace unos misteriosos dibujos de los mismos. A este respecto, no es de extrañar que la cinta española se inscriba en esta tradición hollywoodense -hollywoodista podríamos decir- pues esta será el modelo fundamental que impregnará, en términos de imaginario, el desarrollo del cine de terror en España. Resulta «de una honestidad a valorar mucho más que ciertos intentos artificiales de apostar por determinados fenómenos culturales autóctonos [...] [reconocer que] por encima de todo, ha sido el cine fantástico hollywoodiense el que ha marcado nuestras experiencias [...]» (Alarcón, 2009: 37). En Distancia de rescate también es posible ver la utilización de algunos de estos elementos en la caracterización del niño misterioso, por ejemplo, a través de los dibujos hechos por David, en los que se representan los extraños acontecimientos que ocurren en la novela: «Acá estoy yo con los patos, el perro y los caballos, este es mi dibujo» (Schweblin, 2014: 77). Estos dibujos, acompañados de los nombres de los niños, contribuyen a generar también una atmósfera angustiante, al reflejar, por medio de su factura, la lamentable condición de los infantes intoxicados que acuden a la sala de espera: «algunos ya no controlan bien los brazos, o ya no controlan bien su propia cabeza, o tienen la piel tan fina que, si aprietan demasiado los lápices, terminan sangrándoles los dedos» (2014: 86). 
Como puede apreciarse hasta ahora, El Orfanato y Distancia de rescate comparten algunos rasgos particulares que hacen que una comparación entre ellas resulte productiva. En ambas obras se trata del terror que experimentan los adultos, específicamente las madres -los padres tienen una escasa participación secundaria-, ante la posibilidad de que un devenir monstruoso afecte la entidad de sus propios hijos. Podremos apreciar, por otro lado, algunas diferencias que tienen lugar en el desarrollo de esta temática, pues las dos obras pertenecen a formatos artísticos diferentes, y por tanto se sirven de soportes específicos para generar el efecto terrorífico. Asimismo, cabe preguntarse por la presencia de un sentido político de la representación del niño monstruoso, puesto que la temática se utilizará para vehiculizar un mensaje crítico hacia el vicioso mundo que han construido los adultos.

Ahora bien, la figura del niño monstruoso no pasa solamente por una cuestión de monstruosidad moral, interna, como hemos asumido desde una concepción eminentemente moderna de lo terático (Foucault, 2000: 82), sino también por el aspecto físico. Como veremos, tanto en El orfanato como en Distancia de rescate el terror producido por los niños está vehiculizado también por su apariencia externa, que actúa como correlato de un fondo misterioso que se oculta en su naturaleza. A su vez, la monstruosidad física de los infantes servirá para acusar una serie de vicios del mundo de los adultos. Como señala Sara Martín Alegre, las ficciones de terror «no doubt use the child to portray the faults of the adults, but in the process they offer adult readers disturbing images of victimized and victimizing children» (2001: 105-106). Finalmente los adultos no solo son los responsables de la proliferación de niños monstruosos, sino también son quienes, por medio de su mirada, construyen y proyectan -ab-yectan (cfr. Kristeva. Poderes de la perversión) - el espacio de la monstruosidad.

En Distancia de rescate de Samanta Schweblin (2014) se nos narra la historia de Amanda que, con su hija Nina, se va a pasar una temporada al campo. Ahí conoce a Carla, quien le contará la desgracia ocurrida a su hijo David: víctima de una intoxicación, el pequeño ha sido llevado por la madre a la casa verde, el único lugar en el que podían salvarlo. Allí una especie de bruja ha practicado con el niño una «migración», técnica consistente en trasladar el espíritu del afectado a otro cuerpo. La transacción habría implicado que, a su vez, una presencia desconocida habitara en el cuerpo del infante, en una suerte de intercambio de almas. Amanda no cree demasiado en la historia de Carla, y piensa que la mujer debe estar un poco loca. Sin embargo, cosas muy extrañas empiezan a suceder desde entonces, y Amanda comienza a preguntarse si no habrá algo de verdadero en todo ese asunto. 
La forma de la novela es fundamental: todos los acontecimientos son enunciados en un diálogo entre Amanda y el misterioso David, en un contexto teñido de una inquietante irrealidad. David la presiona para que recuerde rápidamente los acontecimientos y así encontrar, antes de que sea demasiado tarde, «el punto exacto en el que nacen los gusanos» (Schweblin, 2014: 11), un asunto del que nosotros, lectores, nos vamos enterando paulatinamente. Esta es la razón de que la historia sea contada, y entonces la narración se estructura sobre la urgencia de recordar, sin detenerse, y donde el menor descuido puede resultar en una catástrofe.

Por su parte, en El Orfanato de Juan Antonio Bayona (2007) se nos cuenta la historia de Laura, quien regresa junto a su familia al antiguo orfanato en el que pasó su infancia y en el que pretende abrir una residencia para niños con discapacidades. Su hijo Simón mantiene una amistad con unos inquietantes amigos invisibles, con quienes suele jugar a la búsqueda del tesoro: «Te quitan el tesoro, algo que tú quieres mucho [...] Si lo encuentras, te conceden un deseo». Durante una fiesta de inauguración de la residencia, Laura se encuentra con un misterioso niño que lleva una suerte de saco-máscara sobre la cabeza. Ella es atacada por el infante, quien además la encierra en el baño de la casa. Posteriormente, Simón desaparece sin dejar el menor rastro. Laura comenzará a creer que los amigos invisibles de Simón en realidad existen, y que han sido ellos los responsables de su desaparición. Cree que ellos han escondido a Simón para que su madre lo encuentre siguiendo las pistas, como si se tratase del juego de la búsqueda del tesoro.

¿Cómo va a presentarse y desarrollarse, entonces, el tema de los niños monstruosos al interior de ambas obras? En primer lugar hemos de señalar que tanto en El Orfanato como en Distancia de rescate se configura lo fantástico como matriz para el desarrollo de los acontecimientos. Este efecto es entendido tradicionalmente como la vacilación producida por la irrupción de un elemento sobrenatural en un universo que funciona según las reglas del mundo real: «Lo fantástico ocupa el tiempo de esta incertidumbre [...] es la vacilación experimentada por un ser que no conoce más que las leyes naturales, frente a un acontecimiento aparentemente sobrenatural» (Todorov, 1980: 15). Para generar el efecto de lo fantástico, en las obras que nos incumben lo sobrenatural aparecerá referido efectivamente desde el punto de vista de un personaje dominado por un estado febril, lo que nos hace dudar de la veracidad de lo que se cuenta. De acuerdo una vez más con Todorov, esta sería una de las estrategias fundamentales en la constitución del elemento fantástico: «La ambigüedad subsiste hasta el fin de la aventura: ¿realidad o sueño?: 
¿verdad o ilusión?» (1980: 15). En Distancia de rescate no sabemos a ciencia cierta si efectivamente hay otra persona habitando el cuerpo de David, ni tampoco podemos afirmar que el presente de la narración sea el que se nos está contando. La narradora afirma: «Ni siquiera sé si esto realmente está sucediendo» (Schweblin, 2014: 35). La alteración de conciencia se acentúa hacia el final de la novela: «Me parece que tengo fiebre, ¿es por eso que todo es tan confuso?» (78), «¿Qué pasa, David? [...] Es como si estuviera soñando» (87). Todo ello dificulta que la narración de los acontecimientos se lleve a cabo, ante lo cual David llamará la atención a Amanda para que retome el hilo del relato: "Ya me contaste como llegaste hasta acá como cuatro veces [...] Amanda, necesito que te concentres» (79). La narradora se desorienta, reitera partes de la trama, y es cada vez más difícil confiar en sus palabras. Hacia el final, incluso, se sugiere que este diálogo en realidad no ha tenido lugar, y que la presencia de David está siendo imaginada por Amanda: «[Carla] vio que estabas desfalleciente, que alucinabas conmigo» (110), le dice David. La multiplicidad de voces se revela aquí, según esta lectura, como una única voz alucinada.

Del mismo modo, en el caso de El Orfanato, tampoco tenemos la certeza acerca de si los eventos sobrenaturales ocurren realmente: todo puede fundamentarse fácilmente en explicaciones racionales, excepto el encuentro final de Laura con los fantasmas. Pero incluso éstos pueden estar siendo producidos por la mente de la protagonista, dado que ésta se encuentra bajo el efecto de unas píldoras que, justamente en este momento, ha estado ingiriendo compulsivamente. Al más puro estilo de relatos clásicos del género fantástico, como Otra vuelta de tuerca de Henry James, tenemos dos narradoras ambivalentes, que experimentan en carne propia el terror de lo sobrenatural, pero que despiertan también nuestra desconfianza.

A favor de este mismo propósito, en la novela Distancia de rescate, la narración recaerá en terceros personajes, relativizando aún más la veracidad de los acontecimientos. Así, el relato sobre la desgracia ocurrida a David, fundamental dentro de la novela, está puesto en boca de su madre, Carla. Al enfocar la narración desde su punto de vista, mediante un estilo directo, se genera un distanciamiento con respecto a los hechos, y se cuestiona la veracidad de los mismos. Amanda, la protagonista y narradora central, sospecha de la historia sobre la migración del alma que Carla le ha contado: «Quiero decirle a Carla que todo es una gran barbaridad [...] Es que no puedo creerme semejante historia, ¿pero en qué momento de la historia es apropiado indignarse?» (Schweblin, 2014: 28). De este modo los hechos, referidos por un tercero y 
puestos en duda por la narradora principal, se sitúan en una esfera de improbabilidad. El juego de la novela con sus diferentes planos enunciativos apunta a dicho objetivo.

Lo mismo vale para el caso de la cinta de Juan Antonio Bayona, en la que esta indignación ante la creencia de los personajes en el elemento fantástico es vehiculizada por el esposo de Laura y por el personaje de Pilar, la psicóloga de la policía, quien afirma que los supuestos fantasmas no serían otra cosa que «una farsa, un truco de feria». Todo ello fractura la autenticidad del relato de la protagonista, quien, como comentábamos, hacia el final de la cinta acaba viendo a los fantasmas de los niños y también al cadáver de su hijo Simón resucitando. Pero todo ello puede ser leído desde una óptica realista, como decíamos, sobre el antecedente de que Laura ha estado ingiriendo una gran cantidad de pastillas que podrían haber trastocado su percepción de la realidad.

En Distancia de rescate encontramos, por otra parte, que la idea de que el propio hijo se convierta en monstruo constituye una especie de temor obsesivo: «La primera vez que me lo dieron para sostenerlo me angustié muchísimo. Estaba convencida de que le faltaba un dedo. [...] La enfermera dijo que a veces pasa con la anestesia, que uno se persigue un poco, y hasta que no conté otra vez los diez dedos de las manos no me convencí de que todo había salido bien» (16). Esta vez es Carla quien, sometida a un estado de conciencia anómalo, cree percibir que algo no anda bien. La idea de que su hijo pueda ser un monstruo aparece como una obsesión que la persigue, como puede verse, desde el nacimiento de David, y que prefigura de algún modo lo que más adelante ocurrirá con el mismo: "Qué no daría ahora porque a David solo le faltara un dedo» (Ibíd.). Esto nos obliga a que como lectores nos preguntemos si no será acaso la propia Carla quien crea de alguna manera la monstruosidad de David, al proyectar sobre él todos sus miedos y fantasías. Es ella quien, finalmente, lo pone en ese lugar de abyección: «Así que este es mi nuevo David. Este monstruo» (34). Sin embargo, Amanda, la narradora, alcanza a darse cuenta de lo erróneo de culpar a los hijos por una supuesta monstruosidad: «Te llamó monstruo y me quedé pensando también en eso. Debe ser muy triste ser lo que sea que sos ahora y que además tu madre te llame monstruo» (35).

La obsesión con la deformidad física aparece también en Amanda. En el momento en que va con su hija Nina a comprar al pueblo, experimenta una gran ansiedad ante la presencia de Abigaíl, una niña que es descrita del siguiente modo: «[...] renguea tanto que parece un mono [...] tiene una de las piernas muy corta, como si apenas se extendiera por debajo de la rodilla, pero 
aun así tuviera un pie. Cuando levanta la cabeza para mirarnos vemos la frente, una frente enorme que ocupa más de la mitad de la cabeza» (42). El horror de que la propia hija se convierta en un monstruo aflora a raíz de este encuentro. Amanda reflexiona: «Está bien que Nina vea esto, pienso. Está bien que sepa que no todos nacemos iguales, que aprenda a no asustarse» (Ibíd.). Sin embargo, este pensamiento de inclusión es inmediatamente refutado: «Pero secretamente pienso que si esta fuera mi hija no sabría qué hacer. Es algo horroroso» (Ibíd.). De esta manera, Abigaíl -al igual que David- aparece como el reverso fantasmático de la hija. Desde el lugar de abyección en que ha sido situada por su deformidad, materializa el miedo de Amanda.

Por otra parte, en el caso de El Orfanato también encontramos ese temor ante una posible monstruosidad del hijo. Esto se evidencia en la escena de la primera aparición del niño enmascarado. ¿Se trata del fantasma de Tomás? ¿O más bien es Simón, vestido con su ropa y su saco-máscara? La revelación final de la película nos lleva a interpretarlo de esta última forma. En tal caso, la ansiedad provocada por esta primera aparición tendría que ver principalmente con la posibilidad de que esa criatura con su máscara horrenda, que mientras camina emite unos quejidos y ruidos animalescos, sea en realidad Simón. Así lo cree Laura, pero en el momento en que intenta sacar la máscara para ver qué es lo que ocurre con su hijo, es atacada por el misterioso infante.

De este modo, la configuración de los niños como entidad ominosa será provocada, en gran parte, por su deformidad física y la manera en que los demás personajes se hacen cargo de ello. En efecto, en el caso de Distancia de rescate, el personaje de David no solo resulta inquietante para Carla y Amanda por su forma de ser, sino también por su aspecto externo, que, al igual que en el caso de Abigaíl, es remarcado por la narradora, con una insistencia que deja ver nuevamente una obsesión con la idea de lo monstruoso: «Si no fuera por las manchas blancas que tenés en la piel serías un chico normal y corriente» (49), «descubro algunas manchas en tu cuerpo que antes no había visto [...] pienso que sin las manchas hubieras sido un chico realmente lindo» (52), «Tenés los ojos rojos, y la piel, alrededor de los ojos y de la boca, es un poco más fina de lo normal, un poco más rosada» (50). Esa insistencia en hablar de las manchas y otros detalles corporales da cuenta, por el solo hecho de su enunciación por parte de Amanda, de la naturaleza de sus preocupaciones.

Con respecto a lo anterior, no es casual que Nina, la hija que Amanda quiere a toda costa resguardar del peligro, sea descrita como una niña hermosa: «Nina sonríe, tiene una sonrisa divina, tiene hoyuelos y se le frunce un poco la nariz» (24). Nina es una niña bonita, saludable, y llena de energía vital, 
y esta construcción del personaje hace que temamos aún más el peligro que la acecha. El monstruoso David podría, al igual que el veneno campestre que finalmente afecta a la niña y a su madre, contaminarla y convertirla en una criatura extraña. Este es el temor que se manifiesta en la pesadilla que Amanda tiene luego del episodio en que encuentra a David dentro de su casa. En el sueño, Nina aparece como una extraña:

-No soy Nina -dice [...] Se apoya en el respaldo y cruza las piernas de un modo en que nunca antes lo había hecho [...] y empuja hacia mí una lata. [...] Es una lata de arvejas de una marca que no compro, que nunca compraría. Más grande que las nuestras, de un tipo de arveja mucho más duro, rústico y económico. Un producto que jamás elegiría para alimentar a mi familia [...] Nina abre la boca pero no sale ningún sonido. La mantiene abierta unos segundos, muy abierta, como si estuviera gritando o todo lo contrario, como si necesitara una gran cantidad de aire que no pudiera encontrar, es un gesto espantoso que nunca le había visto hacer [...] -Soy David -dice Nina y me sonríe (55-56).

El detalle de la lata de arvejas no es menor: es el elemento extraño que se infiltra en la casa, y actúa como una premonición del desastre final. La lata de arvejas es metonimia del campo tóxico, de las nuevas formas de producción agrícola que suponen un peligro para los habitantes del pueblo. Se traza entonces con claridad el vínculo entre la monstruosidad y la amenaza del campo: al igual que la lata de arvejas, la malformación de los niños es una consecuencia del mundo creado por los adultos.

La deformidad física, sin embargo, no significa lo mismo para los adultos que para los niños, y es este un importante antecedente para comprender desde qué subjetividad está siendo construido el discurso sobre lo monstruoso. $\mathrm{Y}$ es que la sensibilidad ante lo siniestro no es algo innato e inmutable en las culturas, sino que guarda estrecha relación con el grado de inmersión en lo que cada sociedad prohíbe, desecha o reprime. De ahí que, como señala Freud, si bien para un adulto el hecho de que una muñeca cobre vida puede representar una posibilidad siniestra, en algunos casos infantiles «no interviene para nada la angustia, puesto que el niño no tuvo miedo a la animación de sus muñecas, y hasta quizá la deseó» (1919: II, párr. 10). En Distancia de rescate vemos que para Nina no reviste un problema mayor el encontrarse con el tan temido David. Ella actúa con total naturalidad al momento de conocerlo: «Nina aparece sonriente [...] Se la ve divertida y tranquila» (47). Es el alboroto de las dos madres, Amanda y Carla, al irrumpir en la casa para salvarla lo que termina por inquietarla: «-¿Qué pasa? -dice Nina arrugando el entrecejo, a 
punto de llorar» (49). Algo similar ocurre con respecto a Abigaíl, cuyo efecto aterrador sobre Amanda ya ha sido revisado, pero que para Nina no despierta un simple horror, sino más bien una curiosidad y hasta simpatía: "Está agitada, entre divertida y asustada [...] La cajera suspira resignada y da la vuelta para salir del mostrador [y buscar a Abigaíl]. Nina tira de mi mano para que siga a la mujer por el mismo pasillo» (41). Como se ve, aquellos seres temidos por los adultos son afrontados de manera algo más tranquila por parte de Nina, y despiertan en ella un genuino interés.

En el caso de El Orfanato la perspectiva infantil parece ser bastante más cruel. En la cinta, el personaje de Pilar relata cómo sucedió la muerte del pequeño Tomás: «[los otros niños] habían intentado gastarle una broma. Se metieron con Tomás en las grutas y allí le quitaron el saco para ver si se atrevía a salir. No salió nunca de allí. Se ahogó. Encontraron su cadáver cuando bajó la marea». Si hay crimen, es justamente por esa inocencia ambivalente referida por Eagleton al comienzo de este trabajo. No hay verdaderos culpables, pues los niños «estaban jugando» y lo ocurrido solo fue un accidente. En esa línea, podemos decir que el devenir-monstruo del niño en El Orfanato está prefigurado por el desamparo y la nula responsabilidad de los adultos. Es por ello que, tras este episodio funesto y a manera de venganza por la muerte de Tomás, Benigna, la antigua cuidadora del orfanato, puede llevar a cabo la matanza de todos los niños sin que nadie se lo impida, impunemente, pues ellos están en una situación de absoluta desprotección. Son niños que nadie echará de menos, cuyos cadáveres nadie reclamará: no forman parte del ideal de familia, son huérfanos. El niño monstruoso y el crimen en la infancia surgen, pues, del abandono y la indiferencia por parte de los adultos.

Podemos observar, en definitiva, que, si por una parte los adultos niegan y esconden a los niños monstruosos -reflejo de sus propias culpas-, al tiempo que son incapaces de hacerles frente, los otros infantes se sienten, si bien atemorizados, atraídos hacia ellos al mismo tiempo, y buscan perversamente acercárseles para ponerlos a prueba, como gatos jugando con un ratón. Eso es lo que refleja la sonrisa de Nina en Distancia de rescate cuando se encuentra con David y con Abigaíl, la exaltación que siente al estar cerca de ellos, de esa realidad que es parecida a ella, pero a la vez tiene algo de diferente. En esta línea, no es casual tampoco que en El Orfanato Laura deba adquirir un comportamiento infantil y entrar en el juego para poder contactar con los otros niños -hacia el final de la cinta ella ve su propia imagen de niña, y es en ese momento en que consigue compenetrarse con los fantasmas, cosa imposible desde la perspectiva adulta. 
En suma, la angustia sentida ante la malformación de los niños no nos revela tanto una naturaleza «maligna» de los infantes como sí la incapacidad, por parte de los adultos, de comprender y cuidar de sus niños. Asustados, los mayores querrán dar vuelta la cara, esconder a los niños en cuartos sórdidos y huir de ellos. Carla, la madre de David así lo confiesa: «No quería verlo, Amanda. Lo que quería era escapar. Desesperadamente [...] Nos miramos, pero enseguida aparté la vista» (32). La abyección de David es aún más violenta por parte del padre, que «decía cosas feas sobre David. Que no le parecía un chico normal. Que tenerlo en la casa lo hacía sentir incómodo. No quería sentarse a la mesa con él» (80). Este rechazo da cuenta también de cómo los hijos pasan a un segundo plano, a un estado de desprotección debido a la indiferencia de los adultos: «Yo creo que Omar algo sospechaba y prefería no saber [...] más velaba la pérdida de su bendito padrillo prestado» (82-83). El padre no hace nada por ayudar a David, encarna la perspectiva indolente del hombre que vela solo por los asuntos de negocios que el campo le reclama, y de hecho su participación en el relato es mínima. Asimismo, los niños intoxicados y deformes permanecen escondidos en la llamada salita de espera: "Ahí nos dejan antes de que el día empiece. [...] no volvemos a casa hasta la noche. [...] Es difícil cuidar de nosotros en las casas, algunos padres ni siquiera saben cómo hacerlo» (107). Del mismo modo, en El Orfanato, el pequeño Tomás aparece condenado a vivir oculto en un cuarto especial, y a utilizar una máscara para cubrir la deformidad de su rostro cada vez que quiera salir al espacio público. Paradójicamente, esta máscara es bastante más horrorosa que la supuesta fealdad que se pretende tapar con ella. Cuando Tomás aparece sin la máscara, se nos sigue negando una visión detallada de su rostro, por medio de una serie de juegos de cámara que lo sitúan fuera de campo: «la visión parcial es el índice de un peligro inminente, el soporte del suspenso [...] La visión parcial es así el índice de la causa, de la causa del deseo. Ella mantiene el deseo a través del deseo (o el temor) de ver» (Bonitzer, 2007: 70). Como he dicho, a pesar de todo este aparataje y de las expectativas generadas sobre el rostro de Tomás, el verdadero horror surge más bien ante la sucia y húmeda máscara que lo cubre. Si pensamos ahora en el sentido profundo del vocablo «monstruo», vinculado a lo espectacular, a lo visible, al mostrar, monstrare (Insúa, 2009: 149), podemos comprender que todas estas medidas de ocultamiento tienen, en fin, una razón muy simple, a saber, que la monstruosidad no se realiza cuando no se muestra. En este caso, sin embargo, la máscara produce el efecto exactamente contrario.

Pero esta máscara no es simplemente un mecanismo de ocultamiento de la monstruosidad de Tomás. Al profundizar un poco más en el sentido de 
la película, notamos que el valor de este elemento está anclado a la denuncia de una cierta ceguera por parte de los adultos. Siguiendo los planteamientos de Naomi Schor (1999: 94), aquí la máscara funciona como «a metaphor not of but for blindness, for the inability of the sighted to pierce appearances, specially the hideous». Prosigue Schor: «The hideous mask is only the concretization of the symbolic mask behind which the subject hides his or her deepest desires and most intimate nature. And in a paradox that flows from the very notion of monstrosity, what lies behind the repulsive exterior of the monster is goodness» (1999: 95). El funcionamiento de esta metáfora puede verse claramente en la cinta, pues Tomás no es en realidad el ente maligno que todos creen que es, sino solo un niño abandonado, y condenado por su malformación. Pero la ceguera de los adultos, su acto deliberado de no querer ver, impide reconocer la verdadera naturaleza de Tomás. La máscara es el significante que cubre el horror, pero, conforme avanza la película, nos damos cuenta de que lo verdaderamente horrible no es lo que está debajo de la máscara, sino ella misma como signo de la represión e incomprensión de los adultos. Así, lo verdaderamente monstruoso es el comportamiento de los adultos con relación a los niños.

La cinta efectivamente construye este significado. Por ejemplo, en relación con el personaje de Benigna, la antigua cuidadora del orfanato que asesinó a los niños en el pasado, podemos decir que el significante de la máscara aparece para indicar dónde se encuentra el verdadero mal: en la escena en que Benigna es atropellada, ella pasea en un coche de bebé, a modo de objeto fetiche, un muñeco de Tomás enmascarado. ${ }^{1}$ Este elemento, por una parte, sirve como distractor de lo que realmente está pasando, pues Laura corre a revisar el coche creyendo que Simón está ahí -al igual que en el resto de la película, la máscara engaña, hace que se le preste atención y se quiera ver lo que esconde, cuando lo importante está afuera-, pero, por otro lado, el muñeco enmascarado invita a prestar atención a la verdadera monstruosidad que tiene lugar a su alrededor. No es casual que justo en ese momento, cuando Benigna yace muerta en el pavimento, su cara aparezca desfigurada horriblemente y que, después de que se la cubre con un paño -con una máscara-, reviva explosivamente por un par de segundos y se quite el paño de encima,

1 Acerca de este muñeco-Tomás, podría revisarse también lo que Freud («El fetichismo», 1927) señala acerca de la naturaleza del fetiche en relación con la mujer. ¿Benigna cubre el vacío del falo-Tomás con el fetiche de un muñeco que ocupa su lugar? Una lectura de El Orfanato desde el psicoanálisis falocéntrico podría defender la postura de que el terror de la madre funciona sobre la base de una economía fetichista. 
interpelando violentamente a la visión de todos los que la presencian: nos lo está gritando, ella es el monstruo. Nótese por último que el significante del nombre de Benigna articula también una máscara, que señala irónicamente su maldad.

De este modo, los adultos cubren y esconden a los niños monstruosos, para intentar mantener el orden en el mundo exterior, pues son incapaces de hacerse cargo de ellos. Pero estos adultos dan la espalda a lo que ellos mismos han provocado. Como se ha mencionado, el niño monstruoso aparece como consecuencia del mundo devastado y hostil que han creado los adultos: «el mundo que los padres les ofrecen a sus hijos e hijas es un mundo peligroso, una suerte de campo minado en el que el menor descuido, aun en el ámbito doméstico, puede significar un riesgo mortal» (Zamorano, 2015: 2). Esta afirmación acerca de Distancia de rescate es también válida para El Orfanato. En el primer caso, son los sembradíos y una suerte de veneno empleado en el campo lo que desencadena la catástrofe en David y en otros niños, y, más tarde, en la propia Amanda y en Nina. Como señala Carla, esa es efectivamente la causa de que haya tantos niños intoxicados y deformes en el pueblo: «estamos en un campo rodeado de sembrados. Cada dos por tres alguno cae, y si se salva igual queda raro. Los ves por la calle, cuando aprendés a reconocerlos te sorprende la cantidad que hay» (70). Por ello, el sentido crítico que articula la novela por medio de la representación de los niños monstruosos apunta al mundo que han creado los adultos. En este lugar hostil, lo que en un comienzo aparece como un niño amenazante comienza a revelarse, poco a poco, como lo que en realidad es: una víctima.

En el caso de El Orfanato, decíamos, la situación es similar. Hemos visto cómo el desamparo en el que se encuentran los huérfanos desemboca en el crimen, y cómo los adultos son incapaces de lidiar con la deformidad física del pequeño Tomás. La promesa de los adultos, enunciada por el padre de Simón -«Tú no te preocupes porque nosotros vamos a cuidar de ti y no te vas a enfermar, ni mucho menos a morir»-, se rompe. De hecho, apegándonos a una interpretación estrictamente literal de dicha promesa, vemos que en el filme todos los niños -los que vivieron en el antiguo orfanato y Simón- pasan por la enfermedad y luego la muerte. En efecto, los niños del orfanato han sido envenenados -la médium que logra verlos dice «están muy enfermos»-, mientras que Simón es portador del VIH y debe seguir un estricto tratamiento de pastillas. La promesa paterna está incumplida desde el comienzo. Por otro lado, por más que se lo propone, Laura, la Wendy de esta versión terrorífica de Peter Pan (Llampart Pons, 2012: 276), fracasa también en su intento de pro- 
teger a los niños. Tras la desaparición de Simón, ve cómo su sueño se desploma: «¿Quién va a querer que cuide de sus hijos si no soy capaz ni de cuidar del mío?». Es posible diferenciar así el terror de los hijos y el terror por los hijos: el primero es lo que se extraña ante el ominoso mundo de la infancia, eso que impele a los adultos a desviar la mirada, mientras que el segundo temor es el que tiene que ver con el peligro que amenaza la integridad de los niños. Ambas historias son, en definitiva, sobre madres dominadas por un neurótico afán protector y que se ven confrontadas a su miedo más profundo: perder a sus hijos.

Pero la incapacidad de los adultos para proteger a los niños decanta, finalmente, en la tragedia: en El Orfanato el hijo muere dentro de la propia casa, es decir, en el espacio en que debía haber sido protegido. En la novela de Schweblin, la «distancia de rescate», como llama la protagonista a la distancia que la separa de su hija y que le permite calcular la proximidad del peligro (22), está condenada a romperse, y la madre no puede hacer nada al respecto. «¿Fui una mala madre? ¿Es algo que yo provoqué? [...] Fue la distancia de rescate. No funcionó, no vi el peligro» (116). Como señala Rodrigo Zamorano: «Madres y padres fracasan: son incapaces de proteger a sus hijos, $\mathrm{y}$, de alguna forma, han contribuido a crear las condiciones que han provocado sus monstruosidades» (2015: 4). En esta misma línea se inscribe la lectura que hace Llompart Pons sobre el elemento fantástico de El Orfanato, negando toda autenticidad del mismo y proponiendo en su lugar el inmenso vacío de la culpa:

el espectador -que sigue la historia a través de los ojos de Laura- llega a sospechar que ella está culpando a los amigos invisibles por la desaparición de su hijo porque no quiere ver la realidad: la repentina ausencia de su hijo no se debe a seres sobrenaturales, sino a su negligencia: en vez de preocuparse por Simón y su enfermedad, Laura ha optado por volver al orfanato a cuidar de los hijos de los demás y, por ello, tendrá que pagar un precio (2012: 277)

Sin embargo, no me parece que el intento de Laura de abrir una residencia para acoger niños discapacitados constituya una negligencia fatal. Sí, tal vez, el haber hecho caso omiso, al igual que todo el resto de los adultos, a la existencia de los fantasmas de los niños asesinados que Simón se empecinaba en señalar. Tal parece que solo la lectura sobrenatural de El Orfanato presenta algún grado de esperanza para estos niños y sus desesperados padres. Podemos quedarnos, entonces, con la versión en que no hay un castigo moral hacia la madre, pues ella es en realidad la única que se esfuerza por entender 
y salvar a los niños, la única que consigue «creer para ver», como señala Aurora, la médium. De acuerdo con esta lectura, en lugar de la catástrofe, al final tiene lugar la apoteosis del personaje, tras la cual se reúne con su hijo perdido en el más allá, junto a todos los demás niños, bajo la luz del faro «que nos cuida de todos los peligros».

La lectura sobrenatural de Distancia de rescate es, sin embargo, mucho más desesperanzada. A diferencia de El Orfanato, aquí no hay una reunión con los niños afectados, sino una dolorosa e inevitable separación. Los personajes, además, se obstinan en su ceguera. Es solo Amanda la que, desde su estado alucinatorio, consigue percibir algunas cosas. Si creemos su versión de los hechos, encontraremos que su marido, que visita hacia el final la casa de Carla, no consigue ver más allá de la máscara, y no se da cuenta de que Nina ahora habita en el cuerpo de David, según se insinúa al final:

Entonces mi marido te ve [...] está decidido a hacerte bajar. Quiere irse ahora mismo. Erguido contra el asiento, lo mirás a los ojos, como rogándole. Veo a través de mi marido, veo en tus ojos esos otros ojos. El cinturón puesto, las piernas cruzadas sobre el asiento. Una mano estirada apenas hacia el topo de Nina, disimuladamente, los dedos sucios apoyados sobre las patas del peluche, como si intentaran retenerlo (123).

Desde la lectura más realista, los niños aparecen condenados a la intoxicación, y, si optamos por validar la perspectiva sobrenatural, a la pérdida de la identidad y el desconocimiento de los padres. De manera que, a diferencia de El Orfanato, ninguna de las dos alternativas de lectura promete algo de esperanza.

De esta manera, en estas obras se configuran mundos en los que no se puede estar a salvo, que representan un gran peligro para los niños; mundos en los que ellos deben vivir en el desamparo y la indiferencia, sorteando el incesante peligro de morir, y donde cualquier cálculo e intento de protección resulta insuficiente: los hijos se convertirán irremediablemente en monstruos, para recordar a los adultos su culpa.

\section{BiBLIOGRAFÍA}

Alarcón, Tonio L. (2009): «Apocalípticos y desintegrados: una panorámica del cine fantástico español reciente», Dirigido por...: Revista de cine, núm. 393, pp. 36-43. BAyonA, Juan Antonio (dir.) (2007): El Orfanato, Rodar y rodar, España [DVD]. 
Bonitzer, Pascal (2007): «El campo ciego», en El campo ciego. Ensayos sobre el realismo en el cine, Santiago Arcos, Buenos Aires.

Eagleton, Terry (2010): Sobre el mal (trad. Albino Santos Mosquera), Península, Barcelona.

Freud, Sigmund (1919): «Lo ominoso», Obras completas, 2015. Disponible en http:// www.damiantoro.com/frontEnd/images/objetos/LOOMINOSO.pdf

Foucault, Michel. (2000): Los anormales, Fondo de Cultura Económica, México.

KAYSER, Wolfgang (1964): Lo grotesco. Su configuración en pintura y literatura, Nova, Buenos Aires.

Kristeva, Julia (2006): «Sobre la abyección», Poderes de la perversión. Ensayo sobre Louis Ferdinand Céline, 1980, Siglo Veintiuno, Madrid, pp. 7-45.

Llompart Pons, Auba (2012): «Niños que jamás crecerán: Relecturas de Peter Pan en la literatura y el cine de terror», en Muñoz Corcuera, Alfonso y Di Biase, Elisa (eds.). Barrie, Hook, and Peter Pan. Studies in contemporary myth, Cambridge Scholars Publishing, Newcastle, pp. 267-278.

Martín Alegre, Sara (2001): «The child and the monster in four novels by Stephen King», Atlantis, vol. 23, núm. 1, pp 105-114.

PÉrez, Vicente y Andrés GARcía (2005): «Análisis funcional de las estrategias psicológicas de terror en el cine, Estudios de psicología, número 26 (2), pp 237-245.

Salamanca Ballesteros, Alberto (2007): Monstruos ostentos hermafroditas, Universidad de Granada, Granada.

ScHor, Naomi (1999): «Blindness as metaphor», Differences: A journal of Feminist Cultural Studies, vol. 11, núm. 2, pp. 76-105.

Schweblin, Samanta (2014): Distancia de rescate, Random House Mondadori, Buenos Aires.

Todorov, Tzvetan (1980): Introducción a la literatura fantástica, Premia. México D.F.: .

ZAMORANo, Rodrigo (2015): «Niños monstruosos: el terror a los hijos en Flores de Mario Bellatín y Distancia de rescate de Samanta Schweblin». Conferencia dictada en Representaciones e imaginarios de lo monstruoso en la literatura y el arte, Pontificia Universidad Católica de Chile. 